\title{
Genetic Analysis of Iron Chlorosis Tolerance in Myrobalan Plum x
}

\author{
Almond-Peach Hybrids \\ GONZALO MJ ${ }^{1}$, DIRLEWANGER E ${ }^{2}$, LAIGRET $\mathrm{F}^{2}$, MORENO MA ${ }^{1}$, GOGORCENA $\mathrm{Y}^{1}$ \\ ${ }^{I}$ Estación Experimental de Aula Dei (CSIC). Dept. de Pomología. Apdo. 202, 50080 Zaragoza, Spain \\ ${ }^{2}$ INRA, Unité de Recherche sur les Espèces Fruitières et la Vigne (UREFV), BP 81, 33883 Villenave d'Ornon, France
}

Keywords: Iron chlorosis, Prunus rootstock, QTL analysis, Candidate genes.

Iron deficiency is responsible for enormous economical losses in a wide range of crops in the Mediterranean area. Different species vary in their susceptibility from poorly to severely affected leaf chlorosis, one of the main common symptoms for the iron deficiency. The prevention of this nutritional disorder involves the use of tolerant rootstocks as the best alternative to palliate the problem in fruit tree plantations. The genetic control of the tolerance to this abiotic stress in trees is still unknown but studies in other crops suggested that it could be a quantitative trait. For that, this work is directed to understand the genetic control of iron chlorosis in tree fruits. Two approaches are being used: the quantitative genetics with detection of QTLs related with iron chlorosis and the molecular genetic approach with the search of candidates genes differentially expressed under iron deficiency. A $F_{1}$ population derived from a three ways interspecific cross between the myrobalan $(P$. cerasifera): 'P.2175' and the almond $\mathrm{x}$ peach hybrid $(P$. dulcis $\mathrm{x} P$. persica): Felinem (formerly GxN 22) was analyzed. SPAD measurements were performed in the leaves of the $F_{1}$ individuals detecting segregation to iron chlorosis tolerance. Preliminary results showed correlation between the chlorophyll content and genomic regions located in chromosomes 2 and 6, close to other reported QTLs involved in fruit quality and fungus resistance. The candidate genes approach is being implemented based on in silico screening of genes shown to be expressed in response to iron deficiency in roots, such as those encoding FRO2, IRT1 and other candidate genes differentially expressed in grape rootstocks under iron induced chlorosis.

\section{INTRODUCTION}

Iron chlorosis is a common growth disorder affecting a wide range of crops in calcareous soils where the iron is present but is not assimilable by the plant. The problem is particularly important in fruit trees where the use of tolerant rootstocks represent the best alternative to prevent the chlorosis (Socias i Company et al., 1995; Gogorcena et al., 2000; Tagliavini and Rombolà, 2001; Gogorcena et al., 2004). Although the genetic structure of the characters related with iron chlorosis tolerance in trees is unknown, there is some evidence in other plant species that it could be a quantitative trait (Diers et al., 1992; Dasgan et al., 2004) identifying some QTLs involved in the response to this disorder (Diers et al., 1992; Lin et al., 1997). In grapevine, some QTLs affecting the chlorophyll content in leaves and candidates genes, such as FRO2 and IRTI, were 
reported (Decroocq et al., 2006). Furthermore, a hundred DNA fragments from grapevine obtained by cDNA-AFLP were isolated and sequenced, identifying 35 genes differentially expressed in chlorotic conditions and related to iron metabolism (Gogorcena et al., 2006). The main objective of this work is to search genes involved in iron chlorosis tolerance in fruit trees to undertake the selection of rootstock using molecular markers associated with this tolerance. The analysis of tolerance was performed using two different approaches: detection of QTLs and search of candidates genes differentially expressed under iron deficiency.

\section{MATERIAL AND METHODS}

\section{QTL Approach}

The individuals from a $F_{1}$ population derived from a three ways interspecific cross between the myrobalan $(P$. cerasifera): 'P.2175' and a ( $P$. dulcis $\mathrm{x} P$. persica) hybrid: 'Felinem' were analyzed for tolerance to iron chlorosis. Genotyping was performed with SSR markers (Dirlewanger et al., 2004). The trial was carried out in a randomize block design at the Estación Experimental Aula Dei (EEAD), Zaragoza (Spain) during three consecutive years. The chlorophyll (Chl) concentration was estimated using a SPAD 502 meter (Minolta Co., Osaka, Japan). Ten leaves per tree were measured to obtain an average.

QTL analysis was performed by Single Marker Analysis. This analysis fits the data to the simple linear regression model. Significance at the 5\%, 1\%, $0.1 \%$ and $0.01 \%$ levels was estimated, indicating whether the marker is linked to a QTL, as implemented in Windows QTL Cartographer v2.5 (Wang et al., 2006).

\section{Candidate Genes Approach}

Plants from the 'Felinem' parent, provided by Agromillora Catalana S.A. (Subirats, Barcelona, Spain) were grown under hydroponic culture conditions and submitted to different treatments to measure the ferric chelate reductase activity, to take SPAD values (Gogorcena et al., 2000; 2004), to extract chlorophyll from leaves and to isolate the RNA from roots (Chang et al., 1993) to study the differential expression of candidate genes.

In order to establish the relationship between leaf $\mathrm{Chl}$ concentration per unit leaf area and SPAD measurements in this genotype, $\mathrm{Chl}$ was extracted from leaves with $100 \%$ $(\mathrm{v} / \mathrm{v})$ acetone in presence of sodium ascorbate and measured according to Abadía and Abadía (1993).

Plants from 'Felinem' grown in hydroponic culture were submitted to different treatments to understand their response under iron deficiency conditions: Control $(90 \mu \mathrm{M}$ Fe(III)-EDTA), five days deficient (Def), four days deficient re-supplies with $180 \mu \mathrm{M}$ Fe(III)-EDTA during 1 and 2 days (180-1D; 180-2D). The activity of the ferric chelate reductase (FC-R) was measured according to Gogorcena et al., (2000). 


\section{RESULTS AND DISCUSSION}

\section{QTL approach}

The two parentals showed differences in the tolerance to iron chlorosis. 'P.2175' showed greater tolerance while 'Felinem' leaves were yellowing under these soil conditions. The SPAD measurements performed during three consecutive years illustrate the tendency for both parents (Fig. 1). 'P.2175' showed small variation between the ten trees measured and significant differences between years were not observed. However, the 'Felinem' parent, reported as tolerant (Felipe et al., 1997), showed a high variation between trees. The lowest SPAD values and the highest mortality in this genotype suggest problems for adaptation to our soil conditions (Zarrouk et al., 2005).

The $F_{1}$ genotypes were also analyzed for tolerance to iron chlorosis by the SPAD measurements under field conditions. The segregation for these traits during the three years coincided with a normal distribution but the SPAD values were decreased each year following the parent's pattern (Fig. 2). The QTL analysis detected significant molecular markers in chromosomes 2 and 6 by Single Marker Analysis. In these positions, QTLs involved in leaf morphology or nematode resistance were previously reported (Yamamoto et al., 2001; Dirlewanger et al., 2004). However, these results are still preliminary due to the small number of genotypes analyzed. The size of the $F_{1}$ population is increasing every year for that the QTL analysis would be done more accurately.

\section{Candidate Genes Approach}

'Felinem' plants under iron deficient conditions presented a different physiological response. The relationship between SPAD and Chl concentration per unit leaf area is shown in Fig. 3 with a high coefficient of correlation $R^{2}=0.98$. The chlorophyll content was recovered gradually with the iron re-supply (Fig. 4 A) as it was mentioned before in Jiménez (2006). In addition, the FC-R activity increased after 1 or 2 days of re-supply (Fig. 4 B). This induction suggests a moderate tolerance to iron chlorosis probably due to the influence of the almond parent.

The variation observed in physiological parameters suggests differential expression of genes involved in the tolerance to iron chlorosis. Currently, in silico screening of genes expressed in the response to iron deficiency in different plant species is being implemented. The Arabidopsis FRO2 and the IRTI involved in the iron reduction and transport respectively (Vert et al., 2002; Connolly et al., 2003) were used to perform BLAST to the Prunus EST database searching possible homologies in this species. Several primers have been designed to implement real time RT-PCR analysis (Gogorcena et al., 2006) using cDNA obtained from root tissue.

\section{CONCLUSIONS}

Differences in the iron chlorosis tolerance between 'P.2175' and 'Felinem' were observed with a major adaptability of the myrobalan plum to the calcareous soils characteristic from the Mediterranean area. The individuals of the $F_{1}$ population derived from the cross between these two genotypes showed a normal distribution for the SPAD values following the same pattern as the parentals for this nutritional disorder. 
The QTL analysis identified two genomic regions involved in the iron chlorosis tolerance. The localization of these QTLs corresponds with other regions related with different Prunus characteristics. However, the increase of the $\mathrm{F}_{1}$ population that is being gradually carried out in the EEAD is important to confirm these results.

Candidate genes analysis is being implemented to identify genes responsible for tolerance to iron deficiency.

\section{ACKNOWLEDGEMENTS}

This work was supported by the CICYT-Programa Nacional (AGL2005-05533) project, a regional Government (A-44) project and a I3P-PC2006 contract from the CSIC-FSE for M.J. Gonzalo. The authors thank T. Buhner, R. Giménez and S. Jiménez for the help in field measurements and to B. Lafargue for the assistance in the plant material management.

\section{Literature Cited}

Abadía, J. and Abadía, A. 1993. Iron and plant pigments. In: Barton LL, Hemming BC (Eds.). Iron chelation in plants and soils microorganisms. Academic Press, San Diego, California, pp: 327-343.

Chang, S., Puryear, J. and Cairney, J. 1993. A simple and efficient method for isolating RNA from pine trees. Plant Molecular Biology Reporter 11: 113-116.

Connolly, E.L., Campbell N.H., Grotz, N., Prichard, C.L. and Guerinot, M.L. 2003. Overexpression of the FRO2 ferric chelate reductase confers tolerance to growth on low iron and uncovers posttranscriptional control. Plant Physiology 133: 1102-1110.

Dasgan, H.Y., Abak, K., Cakmak, I., Römheld, V. and Sensoy, S. 2004. Inheritance of tolerance to leaf iron deficiency chlorosis in tomato. Euphytica 139: 51-57.

Decroocq, S., Manicki, A., Boury, C., Nemorin, A., Donnart, M. and Ollat, N. 2006. Genetic mapping of some homologous keys genes for iron homeostasis in Vitis. XIIIth Int. Symp. on Iron Nutrition and Interactions in Plants. Montpellier (France) July (S6-póster -24).

Diers, R.W., Cianzio, S.R. and Shoemaker, R.C. 1992. Possible identification of quantitative trait loci affecting iron efficiency in soybean. Journal of Plant Nutrition 15: 2127-2136.

Dirlewanger, E., Cosson, P., Howad, W., Capdeville, G., Bosselut, N., Claverie, M., Voisin, R., Poizat, C., Lafargue, B., Baron, O., Laigret, F., Kleinhentz, M., Arús, P. and Esmenjaud, D. 2004. Microsatellite genetic linkage maps of myrobalan plum and an almon-peach hybrid-location of root-knor nematode resistance genes. Theoretical and Applied Genetics. 109: 827-838.

Felipe, A.J., Gómez-Aparisi, J., Socías, R. and Carrera, M. 1997. The almond x peach hybrid rootstocks breeding program at Zaragoza (Spain). Acta Hort. (ISHS) 451: 259262

Gogorcena, Y., Abadía, J. and Abadía, A. 2000. Induction of in vivo root ferric chelate reductase activity in fruit tree rootstock. Journal of Plant Nutrition 23: 9-21.

Gogorcena, Y., Abadía, J. and Abadía, A. 2004. A new technique for screening ironefficient genotypes in peach rootstocks elicitation of root ferric chelate reductase by 
manipulation of external iron concentrations. Journal of Plant Nutrition 27: 17011715.

Gogorcena, Y., Decroocq, S., Palomo, D., Cantin, O., Donnart, M., Decroocq, V. and Ollat, N. 2006. Differential gene expression in Vitis under iron deficiency: cDNAAFLP. XIIIth Int. Symp. on Iron Nutrition and Interactions in Plants. Montpellier (France) July (S5-póster-12).

Jiménez, S. 2006. Selección de patrones frutales de hueso tolerantes a la clorosis férrica. Aspectos nutricionales y metabólicos. PhD Dissertation, Universidad de Zaragoza.

Lin, S., Cianzio, S. and Showmaker, R. 1997. Mapping genetic loci for iron deficiency chlorosis in soybean. Molecular Breeding 3: 219-229.

Socias i Company, R., Gómez-Aparisi, J. and Felipe, A.J. 1995. A genetical approach to iron chlorosis in deciduous fruit trees. In: Abadía J (Ed.). Iron Nutrition in Soil and Plants. Kluwer Academic Publishers, Dordrecht, Netherlands, pp: 167-174.

Tagliavini, M. and Rombolà, A. D. 2001. Iron deficiency and chlorosis in orchard and vineyard ecosystems. European Journal of Agronomy 15: 71-92.

Vert, G., Grotz, N., Dédaldéchamp, F., Gaymard, F., Guerinot, M.L., Briat, J-F. and Curie, C. 2002. IRT1, an Arabidopsis transporter essential for iron uptake from the soil and for plant growth. The Plant Cell 14: 1223-1233.

Wang, S., Basten, CJ. and Zeng, Z-B. 2006. Windows QTL Cartographer 2.5. Department of Statistics, North Caroline State University, Raleigh, NC. http://statgen.ncsu.edu/qtlcart/WQTLCart.htm

Yamamoto, T., Shimada, T., Imai, T., Yaegaki, H., Haji, T., Matsuta, N., Yamaguchi, M., and Hayashi, T. 2001. Characterization of morphological traits based on a genetic linkage map in peach. Breeding Science 51: 271-278.

Zarrouk, O., Gogorcena , Y., Gómez-Aparisi, J., Betrán, JA. and Moreno, MA. 2005. Influence of almond xpeach hybrids rootstocks on flower and leaf mineral concentration, yield and vigor of two peach cultivars. Scientia Horticulturae 106: 502-514. 


\section{$\underline{\text { Figures }}$}

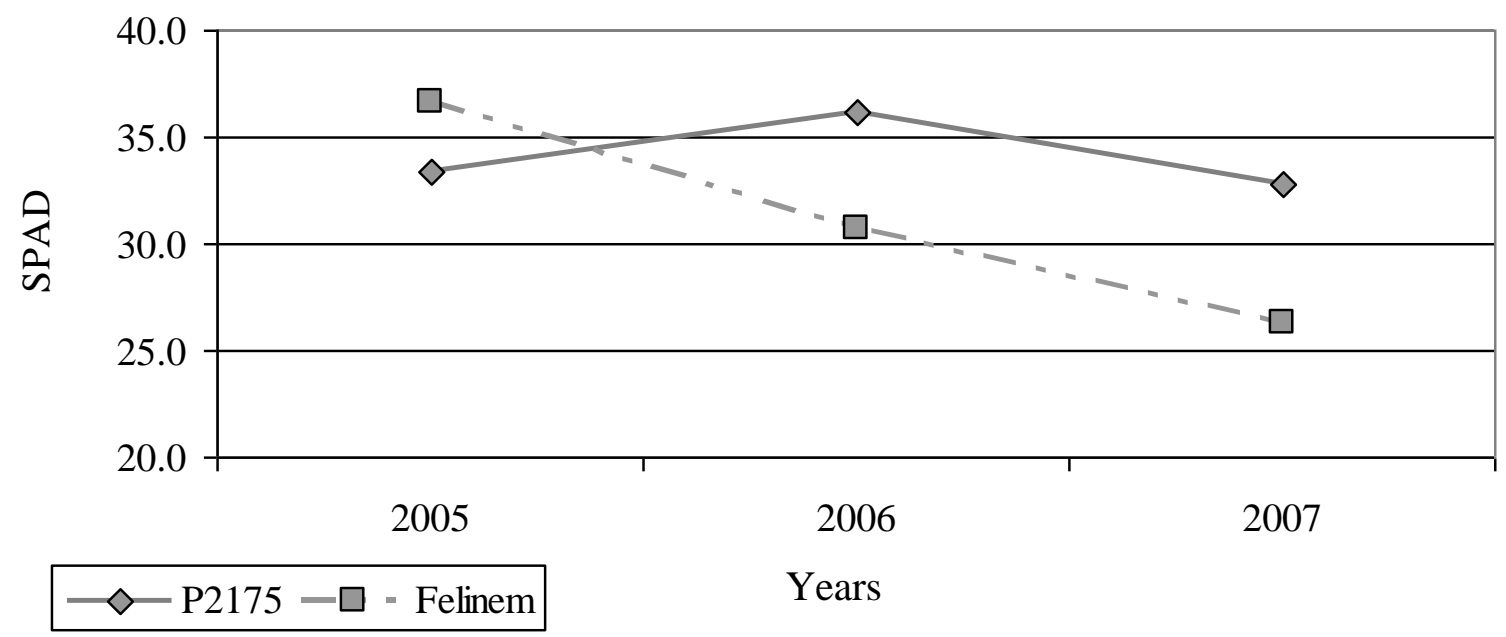

Fig. 1. SPAD values obtained during three consecutive years in the parents of the $\mathrm{F}_{1}$ population.

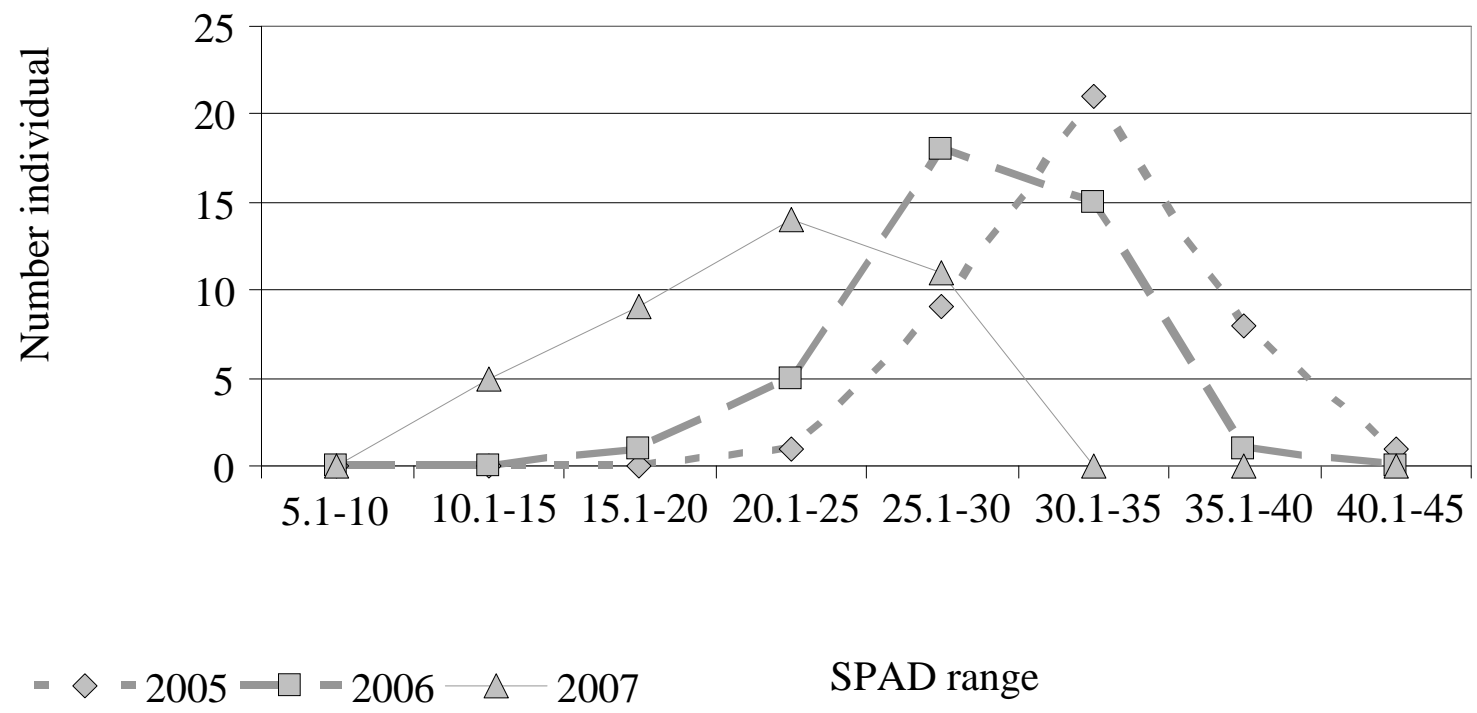

Fig. 2. Distribution of the individuals of the $F_{1}$ population based on the SPAD values. 


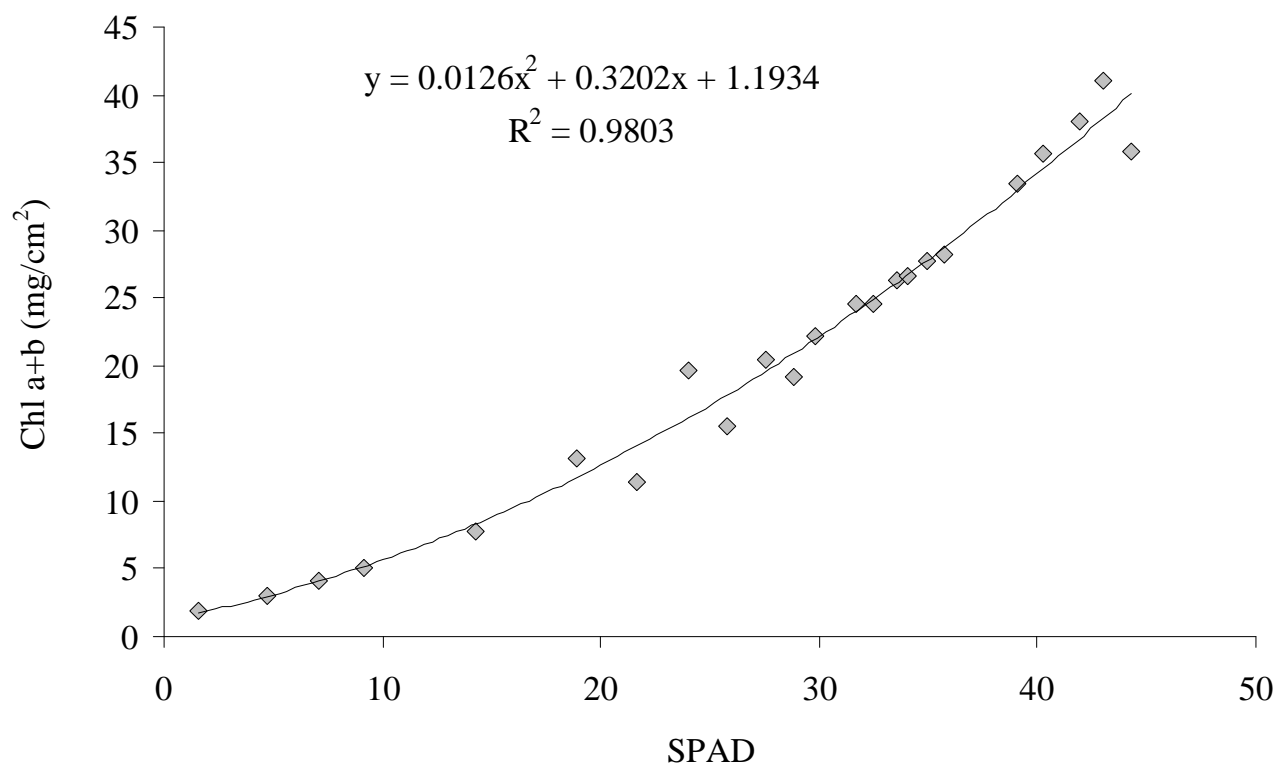

Fig. 3. Relationship between the chlorophyll leaf concentration and the SPAD measurements in the 'Felinem' genotype.
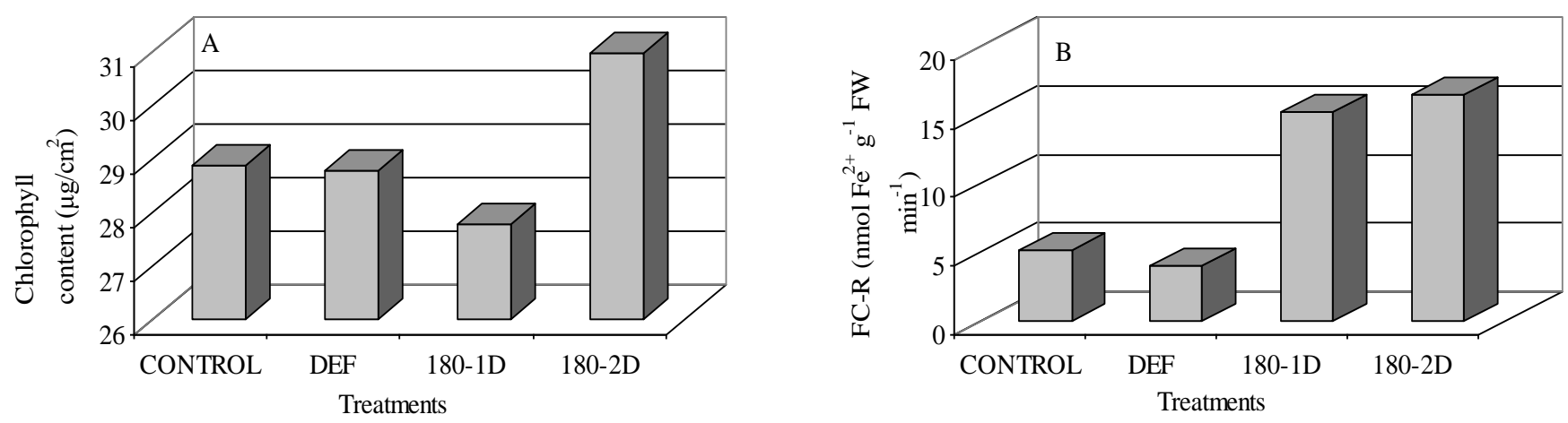

Fig. 4. Response of the 'Felinem' genotype under different iron supplement treatments: Control ( $90 \mu \mathrm{M} \mathrm{Fe}(\mathrm{III})$-EDTA), five days deficient (Def), four days deficient re-supplies with $180 \mu \mathrm{M}$ Fe(III)-EDTA during 1 and 2 days (180-1D; 180-2D). In (A) the chlorophyll content in leaves obtained in the different treatments is represented. In (B) the ferric chelate reductase activity is represented. 